
\title{
BReserch Soute \\ Effects of Fish Oil and Dietary Antioxidant Supplementation on Bone Health
}

\section{Grzegorz Skiba}

Polish Academy of Sciences

\section{Stanisława Raj}

Polish Academy of Sciences

\section{Monika Sobol}

Polish Academy of Sciences

\section{Marian Czauderna \\ Polish Academy of Sciences}

Pawet Kowalczyk ( $\nabla$ p.kowalczyk@ifzz.pl )

Polish Academy of Sciences

\section{Methodology article}

Keywords: fish oil, antioxidant, diet supplementation, lamb femur

Posted Date: November 19th, 2020

DOI: https://doi.org/10.21203/rs.3.rs-107749/v1

License: (c) (i) This work is licensed under a Creative Commons Attribution 4.0 International License.

Read Full License 
1 Effects of fish oil and dietary antioxidant supplementation on bone health

2 Grzegorz Skiba $^{1 *}$, Stanisława Raj ${ }^{1}$, Monika Sobol ${ }^{1}$, Marian Czauderna ${ }^{1}$, Pawel

3 Kowalczyk $^{1^{*}}$

$4{ }^{1}$ The Kielanowski Institute of Animal Physiology and Nutrition, Polish Academy of Sciences,

5 Department of Animal Nutrition, Instytucka 3 Street, 05-110 Jabłonna, Poland

6

7 * Corresponding authors: email g.skiba@ifzz.pl and p.kowalczyk@ifzz.pl

Abstract

Background: Lambs or sheep are considered an excellent animal model for humans owing to advantages related to bone anatomy, formation, biomechanical characteristics; bone strength; and absorption of minerals and vitamins. Moreover, bone healing in many animal species is faster than that in humans, whereas bone healing, turnover, and remodelling in sheep and humans are comparable. In this context, it would be interesting to examine the effects of bioactive components of diet (including Se and carnosic acid) on bone mineralisation and strength, since these are the most important indicators of bone status. This knowledge may be useful in the context of orthopaedic research, recovery after orthopaedic surgeries, and prevention of skeletal diseases in humans.

Results: The aim of the present study was to assess the effects partial replacement of rapeseed oil (RO) with fish oil (FO) combined with dietary supplementation of various antioxidants on the characteristics of lamb femur. Thirty male lambs were assigned to five dietary treatments and fed isoproteinous and isoenergetic diets for 35 days. The control diet was enriched with $3.0 \% \mathrm{RO}$, while the experimental diets were enriched either only with $2.0 \%$ RO and $1.0 \%$ FO or additionally with $0.1 \%$ carnosic acid, $0.1 \%$ carnosic acid and $0.35 \mathrm{ppm}$ Se as selenised yeast, or $0.1 \%$ carnosic acid and $0.35 \mathrm{ppm}$ Se as sodium selenite. After 35 days, the lambs were slaughtered, and the femur was dissected from the carcass of each animal and analysed for morphometric properties.

Conclusions: The present study indicated that dietary bioactive components may improve bone health by promoting bone mineralisation in lambs. Partial replacement of RO with FO combined with dietary supplementation of carnosic acid and organic Se improved the geometric, densitometric, and biomechanical properties of lamb femur. 


\section{Background}

In previous studies, dietary supplementation of n-3 polyunsaturated fatty acids ( $n-3$ PUFA) improved the growth, meat fatty acid profile, fertility, and immunity of pigs $[1,2]$, chicken [3], ruminants [4,5], and rabbits [6]. However, several of these studies used fats rich in n-3 PUFAs, primarily linseed oil [a source of $\alpha$-linolenic acid (ALA, C18:3n-3)] or fish oil [FO; a source of docosahexaenoic acid (DHA, C22:6n-3)] but tested the benefits of n-3 PUFA supplementation of animal feed irrespective of the dietary source. In some studies, n-3 PUFA supplementation of diet improved the fatty acid profile as well as degree of bone mineralisation and bone strength in monogastric animals [2,7]. Thus, dietary supplementation of n-3 PUFA in monogastric animals is beneficial for both animals (by improving their welfare) and humans (by improving the composition of animal products, such as meat). Recently, much scientific efforts was put into the modification of fatty acid profile of ruminant tissues [5,8,9]. However, achieving benefits in this group of animals is rather difficult due to differences in the structure of the gastrointestinal tract. Therefore, studies on the modification of dietary fatty acid composition and its effects on ruminant tissues have been conducted using various feed supplements (e.g. oils or phytochemicals). Moreover, additional studies have been designed to reduce of bacterial lipolysis and subsequently supress biohydrogenation and isomerisation in rumen, mainly through decreasing the enzymatic isomerisation yield of linoleic acid (LA, C18:2n-6) or ALA via inhibition of ruminal bacterial isomerase activity $[10,11,12]$.

Furthermore, Miezeliene et al. [13] proposed that Se regulates the key pathways of antioxidant defence mechanism in the body. In addition, Davis et al. [14] reported that Se is an essential constituent of selenoenzymes, which play pivotal roles in various physiological processes. Se is commonly added to animal diets in an inorganic (sodium selenite) or organic (e.g. selenised yeast) form; however, Gjerlaug-Enger et al. [15] and Rayman [16] demonstrated that the organic form shows greater bioavailability and is more effectively taken up by tissues. Some studies $[17,18]$ indicated that partial replacement of rapeseed oil (RO) with FO [(rich in long-chain n-3 PUFA (LCPUFA)] combined with supplementation of carnosic acid and Se compounds (both organic and inorganic forms) affected rumen isomerisation and biohydrogenation, further decreasing the tissue concentration of undesirable saturated fatty acids (SFA) and increasing the tissue concentration of desirable unsaturated fatty acids (UFA), particularly LCPUFA.

Moreover, according to Rozbicka-Wieczorek et al. [9], such a dietary supplementation decreased oxidative processes in the animal body. Oxidative stress disrupts bone remodelling, consequently reducing bone mass and bone density and increasing bone susceptibility to 
fractures [19]. In addition, some clinical studies [20,21] have shown that antioxidants play important roles in reducing inflammatory processes, which negatively affect bone turnover. Consistent with this, another study [22] in rabbits showed that the combined administration of sodium selenite with vitamins $\mathrm{E}$ and $\mathrm{C}$ (with antioxidant properties) was more effective in preventing structural alterations of bones than the use of vitamins alone.

However, the effects of partial replacement of RO with oils rich in LCPUFA, such as FO, combined with the supplementation of carnosic acid and organic or inorganic Se compounds on bone strength and mineralisation in animal models, especially those other than rodents, remain unknown. Increasing evidence indicates $[23,24]$ that lambs or sheep can serve as an excellent large animal model for humans in studies on orthopaedic or dental defects, owing to advantages related to bone anatomy, formation, and biomechanical characteristics; ease of handling; and absorption of minerals and vitamins. Moreover, bone healing in many non-human animal species is faster than that in humans, whereas this rate is comparable in sheep and humans [25,26]. Additionally, sheep bones have been previously established as useful models for human bone turnover and remodelling [23]. In this context, it seems interesting to assess the effects of dietary supplementation of various oils combined with antioxidants (carnosic acid and organic or inorganic Se compounds) on bone characteristics in a sheep model. These analyses will advance our understanding of the association between dietary supplementation of various antioxidants and bone properties as well as the related metabolic processes. This information will also allow for better design and conduct of research using a lamb model (e.g. the role of natural dietary supplements in orthopaedics, recovery after orthopaedic procedures, and prevention of skeletal diseases).

To this end, we hypothesised that partial replacement of RO with FO combined with supplementation of various antioxidants (carnosic acid and Se compounds) in diets would improve the tissue profile of n-3 PUFA, mineralisation, geometry, and biomechanics of lamb femur. Therefore, the primary aim of the present study was to evaluate the effects of various dietary modifications on femur morphometry, cortical wall thickness (CWT), cross-sectional area (CSA), cortical index (CI), and strength in a lamb model.

\section{Material and Methods}

\subsection{Ethics}

All experimental procedures in this study were performed in accordance with the relevant national or local ethical guidelines and were approved by the III Local Ethics Committee on Animal Experimentation of Warsaw University of Life Sciences, SGGW, 
103 Poland. According to the principles of the 3Rs (replacement, reduction, and refinement), the study and experiments were designed to minimise the number of animals whilst maintaining high statistical power.

\subsection{Animal experiments}

Material for research was obtained from an experiment evaluating the effects of dietary modification on the profile of biohydrogenation products, specifically conjugated fatty acids, in ruminal fluid and some tissues as well as microbiota [18]. The femur was collected, as this bone is commonly used in human osteoporosis and orthopaedic research. Since densitometric measurements are commonly used in human medicine, the present study focused mainly on the state of bone mineralisation owing to its great impact on bone strength.

The study was performed in 30 male Corriedale lambs. The animals were randomly stratified into five groups ( $n=6$ animals each) and individually kept in pens on rubber mats. The main experiment was performed following a 3-week initial period (change in body weight from $\sim 25$ to $30 \mathrm{~kg}$ ). During this period, the lambs were fed only a basal diet (BD) containing $36.0 \%$ meadow hay and $64.0 \%$ concentrate with soybean meal (360 g), barley (165 g), wheat starch (90 g), and a mineral-vitamin mixture (25 g). When lambs reached the body weight of $30 \mathrm{~kg}$, BD was supplemented with 3.0\% RO (group C); RO (2.0\%) + FO (1.0\%) (group EI); $\mathrm{RO}(2.0 \%)+\mathrm{FO}(1.0 \%)+$ carnosic acid $(0.1 \%)($ group EII); RO $(2.0 \%)+\mathrm{FO}(1.0 \%)+$ carnosic acid $(0.1 \%)+$ organic Se $(0.35$ ppm selenised yeast) (group EIII); or RO $(2.0 \%)+$ FO $(1.0 \%)$ + carnosic acid $(0.1 \%)+$ mineral Se $(0.35 \mathrm{ppm}$ sodium selenite) (group EIV). These feeding schemes were maintained for the following 35 days (until the lambs reached $\sim 37.0 \mathrm{~kg}$ body weight).

Feeding schemes as well as feed chemical composition, energy content, and fatty acid concentration are presented in Tables 1-3. During both initial and experimental periods, animals had semi-ad-libitum access to diets ( 0.85 and $1.08 \mathrm{~kg}$. day-1, respectively), offered twice a day (7.30 am and $4.00 \mathrm{pm}$ ) in equal amounts, and ad-libitum access to fresh water. The control and experimental diets were isoenergetic and isonitrogenous and constituted (including supplements) the following contents per kilogram dry matter, according to the feeding recommendations for ruminants [27]: 17.9 MJ gross energy, $202 \mathrm{~g}$ crude protein, $119 \mathrm{~g}$ crude fibre, and $51.7 \mathrm{~g}$ crude fat. RO and commercial odourless FO containing high amounts of LCPUFA were purchased from Agrosol (Pacanów, Poland), and carnosic acid was purchased from Hunan Geneham Biomedical Technology Ltd. (Hunan, China). Selenised yeast 
136 (Saccharomyces cerevisiae) was purchased from Sel-Plex (Alltech In., USA), and sodium selenite was provided by Sigma-Aldrich (St. Louis, MO, USA).

At the end of the main experimental period (35 days), after $12 \mathrm{~h}$ of starvation, each lamb was anesthetised via intramuscular xylazine injection (2-4 mg-10 kg-1 body weight) and then slaughtered by exsanguination. Next, from each right half-carcass, the femur was dissected, cleaned of any remaining flesh, weighed, and frozen $\left(-30^{\circ} \mathrm{C}\right)$ for subsequent analyses.

\subsection{Determination of chemical composition}

Dry matter, nitrogen, ash, crude fibre, and ether extract contents of the diets were determined using the standard methods 934.01, 984.13, 942.05, 978.10, and 920.39 of the Association of Official Analytical Chemists [28], respectively. Fatty acid content of the feeds and each diet component was determined by base- and acid-catalysed methylation, as described by Czauderna et al. [29], followed by quantification using capillary gas chromatography coupled with mass spectrometry (GC-MS), as described by Rozbicka-Wieczorek et al. [9] GCMS-QP2010 Plus EI (Shimadzu, Tokyo, Japan) equipped with a BPX70 fused silica column $(120 \mathrm{~m} \times 0.25 \mathrm{~mm}$ i.d. $\times 0.25 \mu \mathrm{m}$ film thickness; Phenomenex, Torrance, CA, USA), a quadruple mass selective detector (Model $5973 \mathrm{~N}$ ), and an injection port was used, with helium as the carrier gas. Fatty acid methyl esters (FAMEs) were identified by the comparison of electron ionisation spectra of standards (Sigma, St. Louis, MO, USA) and the NIST 2007 reference mass spectra (National Institute of Standard and Technology, Gaithersburg, MD, USA). All FAME analyses were based on total ion current chromatograms and/or selected ion monitoring chromatograms.

\subsection{Densitometric measurements of the femur}

Dual-energy X-ray absorptiometric scans of the femur were obtained using the XR800TM (Norland Medical Systems, CooperSurgical, Fort Atkinson, WI, USA) densitometer scanner according to the manufacturer's protocol of scanning and analysis (research-scan type). A quality assurance test was performed every day to verify the stability of the system calibration (control scans). Moreover, the system was calibrated daily using the QC Phantom and QA Calibration Standard (Norland Medical Systems). Specimens for scanning were thawed at $23^{\circ} \mathrm{C}$ for $12 \mathrm{~h}$ prior to use. During scanning, the right femur was positioned horizontally, with the femoral head facing upwards and the condyles facing downwards, and then scanned from the distal to proximal end. All scans were performed in triplicate to avoid bone rotation, as inconsistencies in the orientation can hamper the accuracy of test results. To ensure consistency, 
170

all scans were performed by the same operator. Bone mineral content (BMC) and bone mineral density (BMD) were recorded.

\subsection{Three-point bending test of the femur}

Following dual-energy X-ray absorptiometry, a three-point bending test was performed using a TA-HDi texture analyser (Stable Micro Systems Ltd.) to determine the biomechanical properties of the right femur, as described by Ferretti et al. [30]. The distance between bone supports was set at $40 \%$ of the femur length, and the measuring head loaded bone samples at the mid-shaft at a constant speed of $50 \mathrm{~mm} \cdot \mathrm{min}-1$. Maximum strength (MS) and maximum elastic strength (MES) of the bone were determined.

\subsection{Geometric measurements of the femur}

Geometric properties of each femur were determined based on the measurements of horizontal and vertical diameters (both external and internal) using an electronic ruler after cutting the bone. CWT (mm), CSA (mm2), and CI (\%) were determined using the following mathematical formulae:

$$
\begin{aligned}
& \text { Cortical wall thickness }(C W T)=\frac{[(V+H)-(v+h)]}{4} \\
& \text { Cross - section area }(C S A)=\frac{\pi \times[(H \times V)-(h \times v)]}{4}
\end{aligned}
$$

$$
\text { Cortical index }(C I)=\left(\left(\frac{H-h}{H}+\frac{V-v}{V}\right) \div 2\right) \times 100
$$

where $V$ is the vertical external diameter $(\mathrm{mm}) ; H$ is the horizontal external diameter $(\mathrm{mm}) ; v$ is the vertical internal diameter $(\mathrm{mm})$; and $h$ is the horizontal internal diameter $(\mathrm{mm})$.

\subsection{Statistical analysis}

Statistical analyses were performed using Statistica (version 12, StatSoft, Tulsa, OK, USA). The examined bone characteristics in different groups are presented as mean values, with statistical errors pooled as standard error. Results were analysed with one-way ANOVA. When the $F$ ratio was significant, Tukey test was used to determine differences between groups. Statistical significance was set at $P<0.05$. With an $\alpha$ level of 0.05 , the power established at 
$80 \%$, and an effect size of 0.75 , the required total sample size was 30 (i.e. $\mathrm{n}=6$ per group). The hypothesised effect size of 0.75 was established based on descriptive statistics of a previous study [2]. Post hoc calculations using the above-mentioned data indicated that the actual power achieved in this study was $81.4 \%$.

\section{Results}

The experimental factors did not affect the growth rate of lambs. There were no significant differences in body weight across lamb groups $(30.5 \pm 0.5$ and $37.3 \pm 0.60 \mathrm{~kg}$ at the beginning and end of the main experiment, respectively).

Femur mass and length did not differ across groups (mean $135 \mathrm{~g}$ and $17.24 \mathrm{~cm}$, respectively Table 4). Femur CWT and CSA did not differ between groups EIII and EI (mean $3.24 \mathrm{~mm}$ and $157 \mathrm{~mm} 2$, respectively); however, values in groups $\mathrm{EIII}(\mathrm{P}=0.0153)$ and $\mathrm{EI}(\mathrm{P}=$ 0.0461) were greater than those in C, EII, and EIV (mean $3.13 \mathrm{~mm}$ and $149 \mathrm{~mm} 2$, respectively). The highest femur CI was recorded in group EIII (39.4\%; P = 0.0315), followed by groups EI and EIV (mean 35.9\%), while the lowest CI was recorded in groups C and EII (mean 35.0\%). The highest femur BMC was recorded in group EIII (37.20 g), followed by groups C, EI, and EII (mean $34.9 \mathrm{~g}$ ), while the lowest BMC was recorded in group EIV (33.9 g; P = 0.0003). The highest femur BMD was recorded in group EIII $(0.768 \mathrm{~g} \cdot \mathrm{cm}-2)$, followed by groups EII, EI, and EIV (mean $0.716 \mathrm{~g} \cdot \mathrm{cm}-2)$, while the lowest BMD was recorded in group C $(0.703 \mathrm{~g} \cdot \mathrm{cm}-2$, $\mathrm{P}=0.0001)$. However, BMD in groups EI and EIV did not significantly differ from values in groups $\mathrm{C}$ and EII. Femur MS was recorded in following order $(\mathrm{P}<0.0002)$ : group EIII $(281 \mathrm{~N})$ $>$ EII and EI (mean $259 \mathrm{~N}$ ) > C and EIV (mean $246 \mathrm{~N}$ ). MES followed the same order as MS

\section{Discussion}

In the present study, the energetic and nutritive value of diets as well as feed intake was equalised in all experimental groups. Thus, the diets offered to lambs in a particular group differed only in terms of the content of LCPUFA in fat source of supplements. Previous studies on the modification of fatty acid composition of diets were designed to reduce bacterial lipolysis and subsequent biohydrogenation and isomerisation in the rumen [10,12].

Lambs or sheep are considered an excellent animal model for humans $[23,24]$, owing to advantages related to bone anatomy, formation, biomechanical characteristics; bone strength; and absorption of minerals and vitamins. Moreover, bone healing in many animal species is faster than that in humans, whereas bone healing [25,26], turnover, and remodelling [23] in 
sheep and humans are comparable. In this context, it would be interesting to examine the effects of bioactive components of diet (including Se and carnosic acid) on bone mineralisation and strength, since these are the most important indicators of bone status. This knowledge may be useful in the context of orthopaedic research, recovery after orthopaedic surgeries, and prevention of skeletal diseases in humans.

Previous studies using porcine [2] and rats [31] models indicated that dietary supplementation of n-3 PUFAs improved bone mineralisation and strength. In the present study, we also found a positive effect of partial replacement of RO (a source of LA) with FO (a source of EPA and DHA) on the tested bone parameters. In the body, elongase and desaturase convert LA to arachidonic acid (AA) [32]. However, both EPA and AA are substrates for the production of eicosanoids, particularly prostaglandins (PGs). PGE2 is a product of $n-6$ PUFA, and PGE3 is a product of n-3 PUFA, and these PGs exert antagonistic effects. PGE2 exerts inflammatory effects, whereas PGE3 exerts anti-inflammatory effects. The inflammatory effects of PGE2 and other inflammatory cytokines (e.g. IL-1, IL-6, and TNF- $\alpha$ ) suppress bone formation and enhance bone resorption [33], possibly through upregulating the osteoclast activator RANKL [34]. However, n-3 PUFA inhibit this reaction [35] and promote osteoblastogenesis in the bone marrow [36] and bone formation [37]. Interestingly, in a rats [31] and pigs [38] model, diets rich in ALA did not affect femur morphology, biomechanical properties, and bone mineral content and density compared with diets rich in LA or SFA. This can be explained by the mammalian fatty acid metabolism: limited desaturases are available in LCPUFA synthesis, leading to low endogenous EPA and DHA levels [32]. Elevated PGE3 synthesis also alters cell membrane structure and fluidity, which facilitates vitamin D permeation, thus playing a crucial role in the active transport of Ca across the cell membrane $[39,40]$. Therefore, if EPA and DHA contents of diet exceed AA content, less substrate is available for eicosanoid synthesis from AA. Thus, this fatty acid composition of diet positively affects bone health.

Carnosic acid is a major bioactive component of rosemary and has been reported to show antioxidant and anti-inflammatory properties [41,42]. Moreover, it enhanced bone formation and inhibited bone resorption [43]. Above cited authors hypothesised that although carnosic acid is degraded in the body, its inhibitory effects on the formation of multinucleated osteoclasts would support the osteoblastic differentiation. According to these authors inhibition of osteoclast formation is the key action of carnosic acid that improves bone health. Unfortunately, however, bone metabolism at the cellular level was not studied in the present study thus, we cannot prove this hypothesis. Regarding the effects of carnosic acid on bone mineralisation, our results indicated that the supplementation of lamb diets with this acid 
improved bone mineral content and bone mineral density to similar extents as did the partial replacement of RO with FO.

Se regulates the key pathways related to antioxidant defence mechanisms in all tissues by controlling glutathione metabolism through major Se-containing antioxidant enzymes. Moreover, Se is an essential nutrient, which plays pivotal roles in various physiological processes as an essential constituent of nearly 25 selenoenzymes, in which it is present as the selenoamino acid selenocysteine [44]. Se is commonly added to animal diets in an inorganic form (sodium selenite). However, owing to low bioavailability [15], much of inorganic Se is excreted from the body and is thus not effectively taken up by tissues, including bones [16]. Moreover, this form of Se may exert pro-oxidant and even toxic effects, particularly at high levels $[45,46]$. Therefore, recently, interest in the organic form of Se has increased because of its better absorption and greater biological effectiveness in pigs [47], broilers [48], beef cattle [49], and laying hens [50]. In a study on rabbits Ebeid et al. [51] found that bioactive compounds (e.g. organic Se) positively affect body metabolism. They hypothesised that the mechanism of action of these bioactive compounds is based on the mitigation of oxidative stress, which consequently protects UFA from peroxidation damage, and these UFA can then be effectively taken up by soft tissues. Thus, similar effects are likely produced in bone, as evidenced by the positive effects of n-3 PUFA on bone parameters in a previous study on rats [31].

In the present study, we found a positive effect of simultaneous administration of a mixture of RO (a source of n-6 PUFA with pro-oxidative properties) and FO (a source of n-3 LCPUFA with antioxidative properties) with carnosic acid and organic Se on the tested bone parameters: geometrical, biomechanical, and densitometric parameters of femur in lambs that received this diet were improved compared with those of lambs that received other diets. The mixture of such bioactive compounds likely acted synergistically on the metabolism of fatty acids in the rumen as well as on their accumulation in the tissues of lambs, including the skeleton.

To the best of our knowledge, no study in the literature has explored the effects of simultaneous administration of carnosic acid and organic Se with a mixture of RO and FO on skeletal metabolism, bone mineralisation, and bone strength in ruminants. The present study demonstrated that a diet containing a mixture of RO and FO enriched with carnosic acid and organic Se improved the tested parameters of lamb femur. Based on previous reports [52], we believe that this effect was caused by the greater efficacy of organic Se than that of inorganic Se in increasing the content of this element in tissues. Inorganic Se is retained in the body for a 
excreted through urine. Studies on rabbits [53], bulls [54], and pigs [55] have demonstrated greater accumulation of organic Se in meat tissues. Other studies have also shown that $\mathrm{Se}$ is an essential dietary nutrient, which plays vital roles in bone health through promoting bone formation during bone turnover $[15,25,56]$ and reducing the risk of bone fracture in both animals $[15,24]$ and humans $[56,57]$. This can be explained by the fact that Se regulates a major part of the antioxidant defence mechanism by controlling glutathione metabolism through the key Se-containing antioxidant enzymes glutathione peroxidase and thioredoxin reductase $[13,58]$. In turn, glutathione peroxidase protects the integrity of unsaturated bonds in membrane phospholipids by preventing damage caused by free radicals, which can initiate lipid peroxidation [58]. Therefore, these properties of Se (and other antioxidants) have been believed to protect body cells from the imbalance between oxidants and antioxidants and subsequent oxidative stress, which is considered to be the primary pathogenesis of skeletal disorders (e.g. low bone mineral density or decreased in bone mass) that make bones more prone to fractures $316[20,59]$.

In summary, a large part of function of maintaining the growth and health of bones is attributed to the balance between osteoclast and osteoblast activities, which regulate bone remodelling. Recent evidence has shown that bioactive substances (e.g. LCPUFA, carnosic acid, and organic Se), including those contained in the diet, play crucial roles in maintaining normal bone remodelling processes and protecting bone health. They prevent and/or relieve oxidative stress, inflammation, and changes in cell membrane structure and fluidity, thereby inhibiting osteocyte apoptosis and mitigating osteoclast activity to ultimately increase osteoblast activity and osteogenesis. Thus, such compounds may be used as dietary supplements for maintaining bone health, preventing skeletal diseases, and facilitating recovery following orthopaedic procedures.

\section{Conclusion}

The present study indicated that dietary bioactive components may improve bone health 330 by promoting bone mineralisation in lambs. Partial replacement of RO with FO combined with 331 dietary supplementation of carnosic acid and organic Se improved the geometric, densitometric, and biomechanical properties of lamb femur. 
334 Table 1. Scheme of the study (diet and supplements consumption by particular group of lambs 335 during main experiment)

\begin{tabular}{|c|c|c|c|c|c|c|c|}
\hline \multirow{3}{*}{$\begin{array}{l}\text { Group/ } \\
\text { diet }\end{array}$} & \multirow{3}{*}{$\begin{array}{c}\text { Preliminary (3 weeks) } \\
\text { Diet }\end{array}$} & \multicolumn{6}{|c|}{ Main experiment (5 weeks) } \\
\hline & & \multirow[t]{2}{*}{ Diet } & \multicolumn{5}{|c|}{ Supplement } \\
\hline & & & $\begin{array}{l}\mathrm{RO} \\
(\%)\end{array}$ & $\begin{array}{l}\text { FO } \\
(\%)\end{array}$ & $\begin{array}{l}\text { Carnosic } \\
\text { acid }(\%)\end{array}$ & $\begin{array}{c}\mathrm{SeY} \\
(\mathrm{ppm})\end{array}$ & $\begin{array}{c}\mathrm{Na}_{2} \mathrm{SeO}_{3} \\
(\mathrm{ppm})\end{array}$ \\
\hline $\mathrm{C}$ & $\mathrm{BD}$ & $\mathrm{BD}$ & 3.0 & - & - & - & - \\
\hline $\mathrm{E}_{\mathrm{I}}$ & $\mathrm{BD}$ & $\mathrm{BD}$ & 2.0 & 1.0 & - & - & - \\
\hline $\mathrm{E}_{\mathrm{II}}$ & $\mathrm{BD}$ & $\mathrm{BD}$ & 2.0 & 1.0 & 0.1 & & \\
\hline $\mathrm{E}_{\text {III }}$ & $\mathrm{BD}$ & $\mathrm{BD}$ & 2.0 & 1.0 & 0.1 & 0.35 & - \\
\hline $\mathrm{E}_{\text {IV }}$ & $\mathrm{BD}$ & $\mathrm{BD}$ & 2.0 & 1.0 & 0.1 & - & 0.35 \\
\hline
\end{tabular}

$\mathrm{C}-$ animals fed basal diet $+3.0 \%$ rapeseed oil; $\mathrm{E}_{\mathrm{I}}-$ animals fed basal diet $+2.0 \%$ rapeseed oil $+1.0 \%$ fish oil $; \mathrm{E}_{\mathrm{II}}-$ animals fed basal diet $+2.0 \%$ rapeseed oil $+1.0 \%$ fish oil $+0.1 \%$ carnosic acid; $\mathrm{E}_{\mathrm{III}}-$ animals fed basal diet $+2.0 \%$ rapeseed oil $+1.0 \%$ fish oil $+0.1 \%$ carnosic acid + $0.35 \mathrm{ppm}$ SeY; EIV - animals fed basal diet $+2.0 \%$ rapeseed oil $+1.0 \%$ fish oil $+0.1 \%$ carnosic acid + 0.35ppm Na $\mathrm{SeO}_{3} ; \mathrm{SeY}$ - selenized yeast (Saccharomyces cerevisiae); $\mathrm{RO}$ - rapeseed oil; FO - fish oil; BD - basal diet (1 kg include: meadow hay - $360 \mathrm{~g}$, concentrate consisting: soybean meal - $360 \mathrm{~g}$, barley - $165 \mathrm{~g}$, wheat starch - $90 \mathrm{~g}$ and mineral-vitamin mixture -25 g); Mineral - Vitamins mixture in the diet provided by POLFAMIX OK (Grodzisk Mazowiecki, 344 Poland), supplied per kg of diet: $\mathrm{g}$ : $\mathrm{Ca} 285, \mathrm{P} \mathrm{16}, \mathrm{Na} 56, \mathrm{Fe}$ as sulphate 1, $\mathrm{Cu}$ as sulphate 0.5, $345 \mathrm{Mn}$ as sulphate 5.8, $\mathrm{Zn}$ as sulphate 7.5; mg: Co as carbonate 42, I as iodate 10, Se as selenite 6; 346 and IU: vit. A 500 000, vit. D3 125 000, vit. E as $\alpha$-tocopherol 25000 
350 Table 2. Chemical composition and energy content in the ingredients of diets

351

\begin{tabular}{|l|c|c|c|c|}
\hline \multirow{2}{*}{ Item } & Meadow hay & \multicolumn{3}{|c|}{ Concentrate } \\
\cline { 3 - 5 } & & Barley meal & Soybean meal & Wheat starch \\
\hline Dry matter (DM), \% & 88.4 & 87.6 & 89.7 & 87.3 \\
\hline In DM, \% & 9.50 & 9.94 & 41.8 & 0.90 \\
\hline crude protein & 27.3 & 2.87 & 4.34 & - \\
\hline crude fibre & 3.40 & 2.50 & 2.25 & 0.09 \\
\hline crude fat & 4.85 & 1.84 & 6.16 & 0.12 \\
\hline ash & 17.1 & 16.3 & 17.8 & 16.7 \\
\hline Gross energy, MJ/kg DM & &
\end{tabular}

352

353 
Table 3. Long chain fatty acid concentration $(\mathrm{g} / \mathrm{kg})$ in the ingredients and diets fed to animals.

\begin{tabular}{|c|c|c|c|c|c|c|c|}
\hline \multirow[t]{3}{*}{ Fatty acids } & \multirow{2}{*}{\multicolumn{4}{|c|}{ Ingredients }} & \multicolumn{3}{|c|}{ Period of the study } \\
\hline & & & & & \multirow{2}{*}{$\begin{array}{c}\text { Preliminary } \\
\text { BD }\end{array}$} & \multicolumn{2}{|c|}{$\begin{array}{l}\text { Main experiment } \\
\text { (diet/group) }\end{array}$} \\
\hline & Concentrate & $\begin{array}{l}\text { Meadow } \\
\text { hay }\end{array}$ & $\mathrm{RO}$ & FO & & $\mathrm{C}$ & $\begin{array}{c}\mathrm{E}_{\mathrm{I}}, \mathrm{E}_{\mathrm{II}}, \mathrm{E}_{\mathrm{III}}, \\
\mathrm{E}_{\mathrm{IV}}\end{array}$ \\
\hline $\begin{array}{l}\text { C18:2 n-6 } \\
\text { (LA) }\end{array}$ & 29.2 & 13.1 & 282.0 & 115.0 & 20.0 & 28.5 & 26.84 \\
\hline $\begin{array}{l}\text { C18:3 n-3 } \\
\text { (ALA) }\end{array}$ & 1.01 & 4.18 & 38.5 & 21.0 & 2.04 & 3.19 & 3.02 \\
\hline $\begin{array}{l}\text { C20:5 n-3 } \\
\text { (EPA) }\end{array}$ & nd & nd & nd & 6.79 & nd & nd & 0.07 \\
\hline $\begin{array}{l}\text { C22:5 n-3 } \\
\text { (DPA) }\end{array}$ & nd & nd & nd & 1.56 & nd & nd & 0.02 \\
\hline $\begin{array}{l}\text { C22:6 n-3 } \\
\text { (DHA) }\end{array}$ & nd & nd & nd & 26.6 & nd & nd & 0.27 \\
\hline
\end{tabular}

$\mathrm{C}-$ animals fed basal diet $+3.0 \%$ rapeseed oil; $\mathrm{E}_{\mathrm{I}}-$ animals fed basal diet $+2.0 \%$ rapeseed oil

$+1.0 \%$ fish oil; $\mathrm{E}_{\mathrm{II}}-$ animals fed basal diet $+2.0 \%$ rapeseed oil $+1.0 \%$ fish oil $+0.1 \%$ carnosic acid; $E_{\text {III }}-$ animals fed basal diet $+2.0 \%$ rapeseed oil $+1.0 \%$ fish oil $+0.1 \%$ carnosic acid + $0.35 \mathrm{ppm}$ SeY $;$ EIV - animals fed basal diet $+2.0 \%$ rapeseed oil $+1.0 \%$ fish oil $+0.1 \%$ carnosic acid + 0.35ppm Na $\mathrm{SeO}_{3} ; \mathrm{SeY}$ - selenized yeast (Saccharomyces cerevisiae); $\mathrm{RO}$ - rapeseed oil; FO - fish oil; BD - basal diet (1 kg include: meadow hay - 360g, concentrate consisting of: soybean meal - 360g, barley - 165g, wheat starch - 90g and mineral-vitamin mixture - 25g); Mineral-Vitamins mixture in the diet provided by POLFAMIX OK (Grodzisk Mazowiecki, Poland), supplied per kg of diet: $\mathrm{g}$ : $\mathrm{Ca} 285, \mathrm{P} \mathrm{16,} \mathrm{Na} \mathrm{56,} \mathrm{Fe} \mathrm{as} \mathrm{sulphate} 1, \mathrm{Cu}$ as sulphate 0.5, $\mathrm{Mn}$ as sulphate 5.8, $\mathrm{Zn}$ as sulphate 7.5; $\mathrm{mg}$ : $\mathrm{Co}$ as carbonate 42 , I as iodate 10, Se as selenite 6; and IU: vit. A 500 000, vit. D3 125 000, vit. E as $\alpha$-tocopherol 25 000; nd - not determined 
Table 4. Femur morphometric, geometric, densitometric and biomechanical properties at the 370 end of the study in lambs

\begin{tabular}{|l|c|c|c|c|c|c|c|}
\hline \multirow{2}{*}{ item } & \multicolumn{5}{|c|}{ Group/diet } & SE & P - \\
\cline { 2 - 6 } & $\mathrm{C}$ & $\mathrm{E}_{\mathrm{I}}$ & $\mathrm{E}_{\mathrm{II}}$ & $\mathrm{E}_{\mathrm{III}}$ & $\mathrm{E}_{\mathrm{IV}}$ & & Value \\
\hline Mass, g & 136 & 137 & 135 & 135 & 132 & 4.09 & 0.9491 \\
\hline Length, cm & 17.3 & 17.4 & 17.2 & 17.4 & 16.9 & 0.20 & 0.3572 \\
\hline CWT, mm & $3.16^{\mathrm{a}}$ & $3.21^{\mathrm{b}}$ & $3.11^{\mathrm{a}}$ & $3.26^{\mathrm{b}}$ & $3.13^{\mathrm{a}}$ & 0.104 & 0.0153 \\
\hline CSA, mm ${ }^{2}$ & $149^{\mathrm{a}}$ & $154^{\mathrm{b}}$ & $149^{\mathrm{a}}$ & $160^{\mathrm{b}}$ & $148^{\mathrm{a}}$ & 4.819 & 0.0461 \\
\hline CI, \% & $34.7^{\mathrm{a}}$ & $35.9^{\mathrm{b}}$ & $35.3^{\mathrm{a}}$ & $39.4^{\mathrm{c}}$ & $36.0^{\mathrm{b}}$ & 1.281 & 0.0315 \\
\hline BMC, g & $34.3^{\mathrm{B}}$ & $35.1^{\mathrm{B}}$ & $35.4^{\mathrm{B}}$ & $37.2^{\mathrm{C}}$ & $33.9^{\mathrm{A}}$ & 0.618 & 0.0003 \\
\hline BMD, g/cm & $0.703^{\mathrm{A}}$ & $0.713^{\mathrm{AB}}$ & $0.725^{\mathrm{B}}$ & $0.768^{\mathrm{C}}$ & $0.710^{\mathrm{AB}}$ & 0.009 & 0.0001 \\
\hline MES, N & $182^{\mathrm{A}}$ & $190^{\mathrm{B}}$ & $188^{\mathrm{B}}$ & $216^{\mathrm{C}}$ & $183^{\mathrm{A}}$ & 5.101 & 0.0006 \\
\hline MS, N & $245^{\mathrm{A}}$ & $261^{\mathrm{B}}$ & $257^{\mathrm{B}}$ & $281^{\mathrm{C}}$ & $247^{\mathrm{A}}$ & 5.509 & 0.0002 \\
\hline
\end{tabular}

$371 \mathrm{C}-$ animals fed basal diet $+3.0 \%$ rapeseed oil; $\mathrm{E}_{\mathrm{I}}-$ animals fed basal diet $+2.0 \%$ rapeseed oil

$372+1.0 \%$ fish oil; $\mathrm{E}_{\mathrm{II}}-$ animals $:$ basal diet $+2.0 \%$ rapeseed oil $+1.0 \%$ fish oil $+0.1 \%$ carnosic

373 acid; $\mathrm{E}_{\mathrm{III}}-$ animals fed basal diet $+2.0 \%$ rapeseed oil $+1.0 \%$ fish oil $+0.1 \%$ carnosic acid +

$3740.35 \mathrm{ppm}$ SeY; $\mathrm{E}_{\mathrm{IV}}-$ animals fed basal diet $+2.0 \%$ rapeseed oil $+1.0 \%$ fish oil $+0.1 \%$ carnosic

375 acid + 0.35ppm Na $\mathrm{NeO}_{3}$; SeY - selenized yeast (Saccharomyces cerevisiae); CWT - cortical

376 wall thickness; CSA - cross sectional area; CI - cortical index; BMC - bone mineral content;

377 BMD - bone mineral density; MES - maximum elastic strength; MS - maximum strength;; SE

378 - pooled standard error of mean; ${ }^{\mathrm{A}, \mathrm{B}, \mathrm{C}}$ mean values within a rows with unlike superscript letters

379 were significantly different at $\mathrm{P}<0.01$; ${ }^{\mathrm{a}, \mathrm{b}, \mathrm{c}}$ mean values within a rows with unlike superscript

380 letters were significantly different at $\mathrm{P}<0.05$. 
383 Supplementation a diet with long-chain n-3 fatty acids improves heath of the bones.

Addition of carnosine acid to a diet containing long-chain fatty acids does not improve bone health.

Long-chain n-3 fatty acids, carnosic acid and selenised yeast shows a synergistic effect and improve bone health in the greatest degree.

\section{Declarations:}

Ethics approval and consent to participate: Authors declare that they have no conflict of interest. This article does not contain any studies with human participants performed by any of the authors.

Consent for publication: All authors have read and agreed to the published version of the manuscript.

Availability of data and material: data and material available at any time upon request of reviewers or potential users

Competing interests: The authors declare that they have no competing interests.

Author Contributions: Conception or design of the work, P.K., G.S.; methodology, S.R., M.Cz.., M.S.; software, P.K., G.S.; validation, G.S.,P.K., S.R., M.S. M.Cz.; formal analysis, G.S. S.R., M.S., M. Cz.,P.K.; investigation, G.S., P.K., S.R., M.S., M.Cz.; interpretation of data for the work, G.S., P.K., S.R., M.S.: drafting the work, M.S., P.K., G.S.; revising it critically for important intellectual content; S.R., G.S., P.K.; resources, G.S., data curation, M.S., G.S., S.R., M.Cz., P.K.; writing of the original draft preparation, G.S., S.R., M.S., P.K.; writing of review and editing, G.S., P.K., S.R., M.S.; visualization, G.S., S.R., P.K..; supervision, G.S. and P.K; project administration, S.R.and G.S; funding acquisition, G.S.

\section{Acknowledgments}

According to 3R (Replacement, Reduction, Refinement) ethical principle the design of the study and experimental techniques used through the analysis allowed to minimize the number of animals with maintaining high statistical precision. There is no way to completely replace live animals with another research model. Thus, lambs have been chosen as a model for humans in the area of orthopedic, bone defects filling due to factors strictly related to bone anatomy, bone turnover and remodeling, biomechanical features, absorption of minerals and vitamins. Moreover, in contrast to other animal species sheep/lambs have a bone healing rate close to humans. 


\section{Funding}

424 This research received no specific grant from any funding agency, commercial or not-for-profit 425 sectors.

426

\section{Conflict of Interest}

428 None.

429

\section{Statement}

431 The amount and source of fat and antioxidants used in animal study could reasonably be 432 expected to be achieved in the human population, e.g., in food products, among other as a 433 component in vegetable salad, as a cooking oil.

434 


\section{LITERATURE}

1. Skiba G, Poławska E, Sobol M, et al. Omega- 6 and omega-3 fatty acids metabolism pathways in the body of pigs fed diets with different sources of fatty acids. Archiv Anim Nutr. 2015; 69, 1-16.

2. Sobol M, Skiba G, Raj S. Dietary n-3 PUFA content as a modulator of the femur properties in growing pigs. Br J Nutr. 2019; 121, 508-518.

3. Konieczka P, Czauderna M, Smulikowska S. The enrichment of chicken meat with omega-3 fatty acids by dietary fish oil or its mixture with rapeseed or flaxseed - Effect of feeding duration dietary fish oil, flaxseed, and rapeseed and n-3 enriched broiler meat. Anim Feed Sci Technol. 2017; 223, $42-52$.

4. Demirel D, Wachira LA, Sinclair RG, et al. Effects of dietary n-3 polyunsaturated fatty acids, breed $91,551-565$.

5. Ebrahimi M, Rajion MA, Goh Y M, et al. Effect of linseed oil dietary supplementation on fatty acid composition and gene expression in adipose tissue of growing goats. Biomed Res. Int. 2013; 94625.

6. Kouba M, Benatmane F, Blochet JE, et al. Effect of linseed diet on lipid oxidation, fatty acid composition of muscle, perirenal fat, and raw and cooked rabbit meat. Meat Sci.2008; 80, 829-834.

7. Bonnet $\mathrm{N} \&$ Ferrari SL Effects of long-term supplementation with omega-3 fatty acids on longitudinal changes in bone mass and microstructure in mice. J Nutr Biochem. 2011; 22, 665-672.

8. Razminowicz RH, Kreuzer M, Leuenberger H, et al. Efficiency of extruded linseed for the finishing of grass-fed steers to counteract a decline of omega-3 fatty acids in the beef. Livest Sci. 2007; 114, $150-163$.

9. Rozbicka-Wieczorek A, Wiesyk E, Krajewska-Bienias K, et al. Supplementation effects of selenocompounds, carnosic acid, and fish oil on concentrations of fatty acids, tocopherols, cholesterol, and amino acids in the livers of lambs. Turkish J Vet Anim Sci.2016; 40, 681-693.

10. Lourenco M, Ramos-Morales E, Wallace RJ. The role of microbes in rumen lipolysis and biohydrogenation and their manipulation. Animal. 2010; 4, 1008-1023.

11. Wasowska I, Maia MR, Niedźwiedzka KM, et al. Influence of fish oil on ruminal biohydrogenation of C18 unsaturated fatty acids. Br J Nutr. 2006; 95, 1199-1211.

12. Morán L, Andrés S, Mateo J, et al. Effect of dietary carnosic acid on meat quality from suckling lambs. Small Ruminant Res. 2014; 121, 314-319.

13. Miezeliene A, Alencikiene G, Gruzauskas R, et al. The effect of dietary selenium supplementation on meat quality of broiler chickens. Biotechnol Agron Soc Environ. 2011; 15, 61-69. 
14. Davis CD, Tsuji PA, Milner, JA. Selenoproteins and cancer prevention. Annu Rev Nutr. 2012; 32, 73-95.

470

471

472

473

474

475

476

477

478

479

480

481

482

483

484

485

486

487

15. Gjerlaug-Enger E, Haug A, Gaarder M. Pig feeds rich in rapeseed products and organic selenium increased omega-3 fatty acids and selenium in pork meat and backfat. Food Sci Nutr. 2015; 3, 120128.

16. Rayman MP. The use of high-selenium yeast to raise selenium status: how does it measure up? $\mathrm{Br}$ J Nutr. 2004; 92, 557-573.

17. Kišidayová S, Mihaliková $K$, Siroka $P$, et al. Effects of inorganic and organic selenium on the fatty acid composition of rumen contents of sheep and the rumen bacteria and ciliated protozoa. Anim Feed Sci Technol.2014; 193, 51-57.

18. Białek M, Czauderna M, Białek A.Partial replacement of rapeseed oil with fish oil, and dietary antioxidants supplementation affects concentrations of biohydrogena-tion products and conjugated fatty acids in rumen and selected lamb tissues. Anim Feed Sci Technol. 2018; 241, 6474.

19. Baek KH, Oh KW, Lee WY, et al. Association of oxidative stress with postmenopausal osteoporosis and the effects of hydrogen peroxide on osteoclast formation in human bone marrow cell cultures. Calcif Tissue Int. 2010; 87, 226-235.

20. B, Michaëlsson K, Helmersson J, Byberg L, et al. Oxidative stress and bone mineral density in elderly men: antioxidant activity of alpha-tocopherol. Free Radic Biol Med. 2009; 47, 668-673.

21. Domazetovic V, Marcucci G, Iantomasi T, et al. Oxidative stress in bone remodeling: role of antioxidants. Clin Cases Miner Bone Metab. 2017; 14, 209-216.

22. Turan B, Can B, Delilbasi E. Selenium combined with vitamin E and vitamin C restores structural alterations of bones in heparin-induced osteoporosis. Clin Rheumatol. 2003; 22, 432-436.

23. Schultz CG, Dier J, Kuchel TR, et al. Serial DXA bone and soft tissue estimations in growing sheep. Br J Med Res. 2015; 10, 1-9.

24. Sartoretto SC, Uzeda MJ, Miguel FB, et al. Sheep as an experimental model for biomaterial implant evaluation. Acta Ortop Bras. 2016; 24, 262-266.

25. Wu ZX, Lei W, Hu YY, et al. Effect of ovariectomy on BMD, micro-architecture and biomechanics of cortical and cancellous bones in a sheep model. Med Eng Phys. 2008; 30, 1112-1118.

26. 27. Zarrinkalam MR, Beard H, Schultz CG, et al. Validation of the sheep as a large animal model for the study of vertebral osteoporosis. Eur Spine J. 2009; 18, 244-253.

27. Strzetelski JA, Brzóska F, Kowalski ZM, et al. Feeding Recommendation for Ruminants and Feed Tables (in Polish). National Research Institute of Animal Production, Krakow Poland, 2014; pp. 392 
28. (AOAC) Association of Official Analytical Chemists. Official Methods of Analysis of AOAC International. 18th ed. Current Through Revision 4. 2011; Gaithersburg (MD): AOAC

503

504

505

506

507

508

509

510

511

512

513

514

515

516

517

518

519

520

521

522

523

524

525

526

527

528

529

530

531

532

533

534

29. Czauderna M, Kowalczyk J, Korniluk K et al. Improved saponification then mild base and acidcatalyzed methylation is a useful method for quantifying fatty acids, with special emphasis on conjugated dienes. Acta Chromatogr. 2007; 18, 59-71.

30. Ferretti JL, Capozza RF, Mondelo N, et al. Interrelationships between densitometric, geometric and mechanical properties of rat femora: inferences concerning mechanical regulation of bone modelling. J Bone Miner Res. 1993; 8, 1389-1396.

31. Lau BY, val Fajardo A, McMeekin L et al. Influence of high-fat diet from differential dietary sources on bone mineral density, bone strength, and bone fatty acid composition in rats. Appl Physiol Nutr Metab. 2010; 35, 598-606.

32. Burdge GC. Metabolism of a-linolenic acid in humans. Prostaglandins Leukot Essent Fatty Acids. $2006 ; 75,161-168$.

33. Watkins BA, Shen CL, McMurtry JP et al. Dietary lipids modulate bone prostaglandin E2 production, insulin-like growth factor-I concentration and formation rate in chicks. J Nutr. 1997; 127, 1084-1091.

34. Hofbauer LC, Heufelder AE. Role of receptor activator of nuclear factor-kappaB ligand and osteoprotegerin in bone cell biology. J Mol Med. 2001; 79, 243-253.

35. Sun D, Krishnan A, Zaman K et al. Dietary n-3 fatty acids decrease osteoclastogenesis and loss of bone mass in ovariectomized mice. J Bone Miner Res. 2003; 18, 1206-1216.

36. Shen CL, Peterson J, Tatum OL et al. Inflammation mediators during osteoblastogenesis. J Med Food. 2008; 11, 105-110.

37. Watkins BA, Li Y, Lippman HE et al. Modulatory effect of omega-3 polyunsaturated fatty acids on osteoblast function and bone metabolism. Prostaglandins Leukot Essent Fatty Acids. 2003; 68, 387398.

38. Weiler HA, Fitzpatrick-Wong SC. Modulation of essential (n-6):(n-3) fatty acid ratios alters fatty acid status but not bone mass in piglets. J Nutr. 2002; 132, 2667-2672.

39. Classen N, Coetzer H, Steinmann CM, et al. The effect of different n-6/n-3 essential fatty acid ratios on calcium balance and bone in rats. Prostaglandins Leukot Essent Fatty Acids. 1995; 53, 13-19.

40. Heaney RP, Carey R, Harkness L. Roles of vitamin D, n-3 polyunsaturated fatty acid, and soy isoflavones in bone health. J Am Diet Assoc. 2005; 105, 1700-1702.

41. Kontogianni VG, Tomic G, Nikolic I, et al. Phytochemical profile of Rosmarinus officinalis and Salvia officinalis extracts and correlation to their antioxidant and anti-proliferative activity. Food Chem. 2013; 136, 120-129. 
42. Nieto G, Ros G, Castillo J. Antioxidant and antimicrobial properties of rosemary (Rosmarinus officinalis, L.). Medicines (Basel). 2018; 5, 98-108.

43. Hagiwara H, Basnet R, Wiyasihati SI, et al. Carnosic acid inhibits the formation of osteoclasts through attenuation of expression of RANKL Pharma Nutrition. 2015; 3, 1-6.

44. Rayman MP. Selenoproteins and human health: Insights from epidemiological data. Biochim Biophys Acta. 2009; 1790, 1533-1540.

45. Seko Y, Saiti Y, Kitahara J, et al. Active oxygen generation by the reaction of selenite with reduced glutathione in vitro 1989; pp. 33-70 in Wendel A, Editor. Selenium in biology and medicine. Springer-Verlag, Berlin, Germany.

46. Spallholz J E. On the nature of selenium toxicity and carcinostatic activity. Free Radic Biol Med. $1994 ; 17,45-64$.

47. Jang YD, Choi HB, Durosoy S, et al. Comparison of bio 7 availability of organic selenium sources in finishing pigs. Asian Austral J Anim Sci. 2010; 23, 931-936.

48. Lisiak D, Janiszewski P, Blicharski T, et al. Effect of selenium selenium source v. seleno-yeast and mineral selenium sources on muscle selenium enrichment and selenium digestibility in broiler chickens. Br J Nutr. 2014; 110, 617-624.

49. Juniper DT, Phipps RH, Ramos-Morales E, et al. Effect of dietary supplementation with seleniumenriched yeast or sodium selenite on selenium tissue distribution and meat quality in beef cattle. J Anim Sci. 2008; 86, 3100-3109.

50. Delezie, EM, Rovers A, Van der Aa, et al. Comparing responses to different selenium sources and dosages in laying hens. Poult Sci. 2014;93, 3083-3090.

51. Ebeid T, Zeweil H, Basyony M, et al. Fortification of rabbit diets with vitamin E or selenium affects growth performance, lipid peroxidation, oxidative status and immune response in growing rabbits. Livest Sci. 2013; 155, 323-331.

52. Kanački Z, Ružić Z.The effect of different forms of selenium in diet on liver function and body weight of broiler chickens. Veterinaria. 2014; 63, 29-36.

53. Amer SA, Omar AE, Abd El-Hack ME Effects of Selenium- and Chromium-enriche of diets on growth performance, lipid profile, and mineral concentration in different tissues of growing rabbits. Biol Trace Elem Res. 2019; 187, 92-99.

54. Haug A, Vhile SG, Berg J, et al. Feeding potentially health promoting nutrients to finishing bulls changes meat composition and allow for product health claims. Meat Sci. 2018; 145, 461-468.

55. Jiang J, Tang $X, X$ ue $Y$ et al. Dietary linseed oil supplemented with organic selenium improved the fatty acid nutritional profile, muscular selenium deposition, water retention, and tenderness of fresh pork. Meat Sci. 2017; 131, 99-106. 
569 56. Zeng H, Cao JJ, Combs G F Jr Selenium in bone health: roles in antioxidant protection and cell proliferation. Nutrients. 2012; 5, 97-110.

57. Hoeg A, Gogakos A, Murphy E, et al. Bone turnover and bone mineral density are independently related to selenium status in healthy euthyroid postmenopausal women. J Clin Endocrinol Metab. 2012; 97, 4061-4070.

574 58. Jiang Z, Lin Y, Zhou G et al. Effects of dietary selenomethionine supplementation on growth performance, meat quality and antioxidant property in yellow broilers. 2009; 57, 9769-9772.

59. Banfi G, Iorio EL, Corsi MM Oxidative stress, free radicals and bone remodeling. Clin. Chem Lab

578 